\title{
A VOZ QUE APROXIMA: O LEITOR EM TEMPOS DE RECLUSÁO
}

\section{THE VOICE THAT BRINGS CLOSER: THE READER IN TIMES OF RECLUSION}

\author{
Daniela Favero Netto \\ Universidade Federal do Rio Grande do Sul, UFRGS, RS, Brasil \\ Magali Lopes Endruweit \\ Universidade Federal do Rio Grande do Sul, UFRGS, RS, Brasil
}

Resumo: Partindo de consideraçôes sobre por que ler os clássicos, refletimos sobre o lugar do leitor nos tempos atuais, buscando problematizar o seguinte: quem é o leitor de hoje? Baseamonos na definiçấo de leitor incomum, sustentada por parâmetros inscritos no século XVIII, confrontando-a com as características do leitor do século XXI, atingido por uma pandemia que o isola. Usamos a experiência do grupo de leitura intitulado "Lendo os clássicos em voz alta" e a análise de relatos dos participantes para entender em que medida a leitura em voz alta é capaz de construir um novo leitor, um leitor de 2020.

Palavras-chave: Leitura de clássicos; leitura em voz alta; leitor em reclusão.

Abstract: Based on considerations about why reading classic books, we reflect on the place of the reader in the current times, aiming to problematize the following: who is today's reader? We start comparing the definition of uncommon reader, supported by the parameters inscribed in the 18 th century, with the characteristics of the reader in the 21 st century, affected by a pandemic that isolates him/her. We use the experience of the reading group named "Lendo os clássicos em voz alta" [Reading the classics aloud] and the analysis of participants' testimonies in order to understand how reading aloud is able to form a new reader, a 2020's reader.

Keywords: Reading classic books; reading aloud; reader in reclusion.

\section{Ler os clássicos para enxergar o mundo}

"A única razão que se pode apresentar é que ler os clássicos é melhor do que não ler os clássicos." 
A epígrafe acima abre - com certa ironia - o primeiro ponto desta discussão: como justificar a escolha de ler um livro considerado clássico, tão distante do mundo atual, em vez de ler uma obra que atenda aos anseios de nossa modernidade? É claro que Ítalo Calvino não pretende responder de uma forma tão simplista a essa questão, muito menos nós o pretenderíamos aqui; o que buscamos é trazer à baila o assunto, lançá-lo ao vento para que mais vozes falem dele. Sobretudo buscamos problematizar uma pergunta costumeiramente feita pelos alunos, "por que optar por ler um clássico?", ao mesmo tempo em que justificamos o título de nosso projeto de extensão', que despretensiosamente tornou-se também objeto de pesquisa: "Lendo os clássicos em voz alta”.

A primeira leitura de um clássico que fizemos em voz alta foi motivada pelo desejo de ler sem nenhuma cobrança, seguindo um ritmo próprio, sem precisar prestar contas do que foi lido, pois éramos todos curiosos sem conhecimento profundo da obra. Talvez essa descrição nos colocasse ao lado do leitor comum - em certo modo, a outra face do mesmo leitor incomum definido por George Steiner, não seu oposto ${ }^{2}-$, o leitor dos tempos atuais: olhando o relógio e, de quando em quando, o celular. Leitores de um tempo distante da época em que os clássicos foram escritos. Leitores do ano 2020, eis nossa condição.

Nas palavras de Calvino ([2002] 2018, p. 14-15), em Por que ler os clássicos,

[...] o dia de hoje pode ser banal e mortificante, mas é sempre um ponto em que nos situamos para olhar para a frente ou para trás. Para poder ler os clássicos, temos de definir "de onde" eles estão sendo lidos, caso contrário tanto o livro quanto o leitor se perdem numa nuvem atemporal

Ao tomar a distância temporal do clássico como um empecilho para a leitura, estamos reforçando a ideia de que não nos sentimos atraídos por uma leitura distante dos problemas da modernidade e do mundo onde vivemos. No entanto, aceitar essa diferença de tempo, de costumes e de forma de viver,

${ }^{1}$ Projeto de extensão, criado em 2017, no Instituto de Letras da Universidade Federal do Rio Grande do Sul (UFRGS), cujos participantes se reúnem uma vez por semana para ler livros clássicos em voz alta. Nesses três anos, foi possível ler Ilíada, de Homero, $\mathbf{O}$ paraíso perdido, de John Milton e Grande sertáo: veredas, de Guimarães Rosa. Com a pandemia, em outros termos, como se verá mais adiante, lemos O idiota, de Fiódor Dostoiévski e Dom Quixote de la Mancha, de Cervantes; e a leitura de Crime e castigo, de Fiódor Dostoiévski, está em andamento.

${ }^{2}$ Trataremos dessa definição mais adiante. 
percebendo a mudança de ritmo descoberta em um livro cujas vidas jamais serão abaladas por problemas como os nossos, torna-se um contraponto enriquecedor, indispensável para compreender a complexidade da vida humana, sem tentar abdicar do tempo presente. É, na verdade, um exercício de alteridade entre o mundo atual, que nos constitui e do qual náo podemos prescindir, e o passado, que nos enriquece, pois "é clássico aquilo que tende a relegar as atualidades à posição de barulho de fundo, mas ao mesmo tempo náo pode prescindir desse barulho de fundo" (CALVINO, [2002] 2018, p. 15). Somos entáo esse leitor que foi formado em um mundo em movimento, que se tornou leitor em ambientes expostos a ruídos, música, vozes e, assim, aprendeu a se relacionar com a leitura de forma diversa. Essa leitura será, portanto, um exercício de pausa e experiência com o diferente e o distante que o clássico pode fornecer.

E ser distante não é necessariamente a condição para ser lido como clássico. Podemos tomar por clássico uma obra antiga ou moderna, desde que possamos reconhecer que ela ocupa "um lugar próprio numa continuidade cultural” (CALVINO, [2002] 2018, p. 14), fazendo parte da história de um povo e de uma língua e, de certa forma, ajudando a preservar a memória da humanidade. Esse capital cultural desempenhado pelo clássico - por toda literatura, a bem da verdade - é um direito de que todos devemos usufruir, visto fazermos parte de uma comunidade com a qual mantemos laços de continuidade e de pertencimento.

Ainda precisamos lembrar que um clássico será sempre uma obra atual, "é um livro que nunca terminou de dizer aquilo que tinha para dizer" (CALVINO, [2002] 2018, p. 11), não será ultrapassado porque sua história segue sendo contada até os dias de hoje: nossas dores se igualam às das personagens de tantos séculos passados. Como afirma Antoine Compagnon (2012, p. 62) em Literatura para quê?, "o texto literário me fala de mim e dos outros; provoca minha compaixão; quando leio eu me identifico com os outros e sou afetado por seu destino; suas felicidades e seu sofrimentos são momentaneamente meus".

Trata-se de ampliar o conhecimento humano e a forma de ver o mundo, ao mesmo tempo tendo a possibilidade de humanizar-se, mostrando nosso pertencimento a uma comunidade ao partilhar da língua, das narrativas da criação de um povo, de seus mitos: itens essenciais para a construção da subjetividade e a construção da própria história. "Os clássicos servem para entender quem somos", nos diz Calvino ([2002], 2018, p. 16). Ao olharmos para nós, seremos mais aptos a olhar para o mundo e entender 
sua perplexidade, "nos tornar mais próximos dos seres humanos que nos cercam, nos fazer compreender melhor o mundo e nos ajudar a viver", nas palavras de Tzvetan Todorov (2019, p. 76).

Essas são, portanto, algumas razóes para lermos os clássicos, compartilhando a leitura com um grupo de pessoas cuja proximidade permitirá momentos de interiorização e reflexão conjunta. Isso porque, conforme o historiador Dante Gallian (2017, p. 175), em A literatura como remédio: os clássicos e a saúde da alma, a obra nos apresenta

[...] de forma magistral, o "problema" do humano enquanto questão eterna e universal, para além das circunstâncias históricas e culturais. Assim, inevitavelmente, a leitura de um clássico suscitará o reconhecimento dessas questóes essenciais da existência humana, despertando no leitor a curiosidade e o desejo de enfrentá-las.

De um hábito em construção, vimo-nos obrigados a construir um novo hábito: ler clássicos em grupo sem, entretanto, estarmos em grupo. Sobre esse processo que discorreremos neste texto, dialogando com autores que se voltaram a refletir sobre a importância da leitura literária e sobre o leitor. Em especial, refletiremos sobre o processo de ler com o outro e para o outro, pois os momentos de leitura conjunta possuem ainda outro componente decisivo para as questóes aqui levantadas: todos emprestam a voz para construir a história lida. Tratemos desse assunto a seguir.

\section{Emprestar a voz para soprar a vida}

Quando Walter Benjamin, em seu ensaio intitulado $O$ narrador: consideraçôes sobre a obra de Nikolai Leskov ([1936] 2012), tributou a morte da narrativa ao surgimento do romance, seu argumento apontava para uma leitura solipsista, sem a possibilidade de compartilhar esse momento, dividida apenas entre leitor e livro. Uma leitura que se distanciava das histórias narradas por um grupo de pessoas em interaçáo, principalmente pelo fato de serem contadas, e náo lidas silenciosamente. De um lado, o silêncio do livro; de outro, a voz da narrativa.

O silêncio dessa leitura centrada apenas no leitor exige um esforço consciente para construir cada personagem com suas próprias características, contando apenas consigo, suas leituras passadas e sua visáo de mundo para conduzir a história e dar sentido ao texto. Tarefa difícil para um jovem leitor. 
Por outro lado, a narrativa compartilhada está presente em todos os momentos da vida: nós contamos histórias. Ao contar, podemos intervir, mudar a ordem dos fatos, emitir julgamentos, enfim, participar do que estamos contando. Além desse sentimento de pertencimento, há um fator preponderante na narrativa compartilhada que a faz ser tão receptiva: a voz. Dessa reflexão, unindo clássicos e voz, construímos as bases para a formação do grupo de leitura em voz alta; e, nas palavras da antropóloga Michèle Petit (2009, p. 58), em A arte de ler ou como resistir à adversidade, constatamos que "o gosto pela leitura deriva, em grande medida, dessas intersubjetividades e deve muito à voz".

O exercício da leitura em grupo é, sobretudo, a assunção da intersubjetividade, possibilitando aos participantes experimentar a alteridade, a importância do outro na construção de si e da própria subjetividade. Segundo Petit (2009, p. 51),

[...] do nascimento à velhice, pensamos unicamente em resposta ao que nos foi lançado por outros [...]. Sem o outro não existe sujeito. Em outras palavras, o gesto da partilha ou da troca, a relação, está na origem mesma da interioridade, que não é um poço onde se mergulha, mas que se constitui entre dois, a partir de um movimento em direçẫo ao outro. Está também na origem mesma da identidade (se é que esta existe, o que pode ser discutido), que se constitui em um movimento simultaneamente centrífugo e centrípeto, em um impulso em direçấo ao outro, um desarraigamento de si, uma curiosidade - uma vontade também, por vezes, feroz. $\mathrm{Na}$ origem mesma da cultura.

Desse movimento em direção ao outro se vale a leitura em voz alta. Ouvir a voz do outro é relembrar as vozes da infância, porque desde o início fomos amparados e recebidos pela voz de alguém que nos mostrou o mundo, nomeou os objetos ao redor, trazendo a trilha sonora de nossa herança nas histórias da infância. Por isso, alguém emprestar a voz, deixando que sua entonaçáo e seu ritmo ajudem a definir uma personagem, construam o cenário por onde a imaginaçáo passeie, é um gesto de generosidade, de acolhimento: é para mim que está sendo contada a história. Não há mais solidão na leitura; há partilha.

Ao ouvirmos a leitura em grupo, vamos intercambiar impressóes, construindo conjuntamente o sentido - é a soma das vozes trazendo à luz o oculto nas entrelinhas. Essa leitura conjunta tem algo de revelador, como se possibilitasse o surgimento de uma verdade invisível para o leitor solitário. É a leitura do outro que me guia para o entendimento. 
As religióes descobriram o poder da voz tão logo estabeleceram os textos fundamentais e os declararam sagrados, tornando-os objetos de adoração. Segundo Martin Puchner (2019, p. 84), em O mundo da escrita: como a literatura transformou a civilizaçáo, "ler em voz alta e interpretar palavras escritas tornou-se importante atividade religiosa, fazendo da religião uma questão de literatura. [...] Tornou-se necessário ler entre as linhas e criar interpretaçóes engenhosas que pudessem revelar verdades ocultas". Dessa prática, até hoje, a leitura em voz alta dos textos sagrados guia o entendimento dos fiéis, une a crença, elegendo uma leitura reveladora da integridade e da verdade contida no texto. A voz conduz à verdade.

Essa verdade revelada por um eleito - aquele exclusivo leitor capaz de emprestar sua voz ao texto e apto a entendê-lo - submete os ouvintes a uma única interpretação como sendo a possível, a melhor e a correta, fechando qualquer possibilidade para novas interpretaçóes: agora nenhuma outra leitura será possível, todos só podem ouvir.

A sacralidade do texto o leva para muito distante do leitor comum, criando a figura do leitor especialista, aquele que vai ler em voz alta e explicar o que todos ouviram. Talvez essa ideia de leitura como sendo possível a poucos dotados de uma sabedoria especial tenha contribuído para afastar leitores de obras consideradas difíceis (os clássicos, por exemplo), podendo apenas ser compreendidas quando lidas com a supervisão de um especialista, um professor perito em determinado autor ou período literário ${ }^{3}$. Quando já somos leitores, queremos saber mais sobre o livro lido, o que outros leitores pensam e como o avaliam, mas, se atribuirmos a outros o entendimento do que lemos e ouvimos, perdemos a chance de construir hipóteses de interpretação, perdemos a oportunidade de confrontar tais suposiçóes com a experiência vivida e, assim, elaborar teorias, analisando a atitude das personagens em relação as suas próprias decisóes, ocupando um lugar singular, seu lugar de sujeito ${ }^{4}$.

Tal é o exercício do grupo "Lendo os clássicos em voz alta": oportunizar que cada participante empreste sua voz, imprima seu ritmo e discuta a leitura, ouvindo e falando, construindo conjuntamente o entendimento

\footnotetext{
${ }^{3}$ Não desconhecemos a importância dos estudiosos das obras literárias e sua contribuição ao estudá-las. Nossa crítica se destina ao entendimento de que apenas uma leitura é possível.

${ }^{4}$ Usamos aqui uma definição lato sensu de sujeito derivada do conceito de sujeito da linguística da enunciação de Émile Benveniste, que é a "constituiçáo do homem na linguagem e pela linguagem" (FLORES, 2009, p. 220). Entendemos que, ao se fazer ouvir no grupo de leitura, ensaiando interpretaçôes e, para tanto, usando a língua, os participantes estão se construindo como sujeitos.
} 
da obra, aceitando ainda a possibilidade de que haja mais de uma maneira de compreender. Se somos muitos, muitas verdades poderão surgir desse trabalho com muitas vozes e várias interpretaçôes. Quem sabe estamos nos construindo leitores diferentes dos que nos antecederam, criando novas possibilidades de repartir leituras e entendimentos.

Novos tempos pedem novos leitores - leitores dos tempos de reclusão.

\section{Do leitor incomum de Steiner ao leitor incomum da pandemia ou do leitor de 1734 ao leitor de 2020}

O leitor incomum, que, em seu ensaio homônimo, escrito em 1978, o crítico e ensaísta George Steiner ([1996] 2018) nos apresenta, é ilustrado, sob seu ponto de vista - recorrendo às artes visuais -, pelo quadro Le Philosophe Lisant, de Chardin, de 1734. Trata-se de um leitor, conforme descreve o autor, cuja memória permite-lhe responder ao texto a partir da compreensão crítica do que foi lido, reconhecendo sempre o poder emanado da palavra escrita, em uma espécie de dever inerente ao ato de ler.

A capacidade mnemônica do leitor incomum de Steiner ([1996] 2018) viabiliza a sua reação imediata à leitura, que é voraz; com sua pena, esse leitor faz notaçóes rigorosas de concordância, de desconfiança ou de embate com o livro. Todas elas compóem um diálogo que o leitor, e só aquele leitor, pode estabelecer; porque o leitor incomum tem, de cor, guardadas todas as suas leituras anteriores. A relação de interdependência que se estabelece entre o leitor incomum Steiner ([1996] 2018) e a palavra lida no livro é criativa e é erudita, e é, para Steiner, também ideal. Trata-se de um leitor cujas leituras fundantes (da literatura, mas também dele) estão nele, por redundante que pareça, porque advêm de um ato ritualístico da relação homem x livro, ou seria homem + livro? Eis a imagem escolhida por Steiner ([1996] 2018) para o seu leitor incomum: 


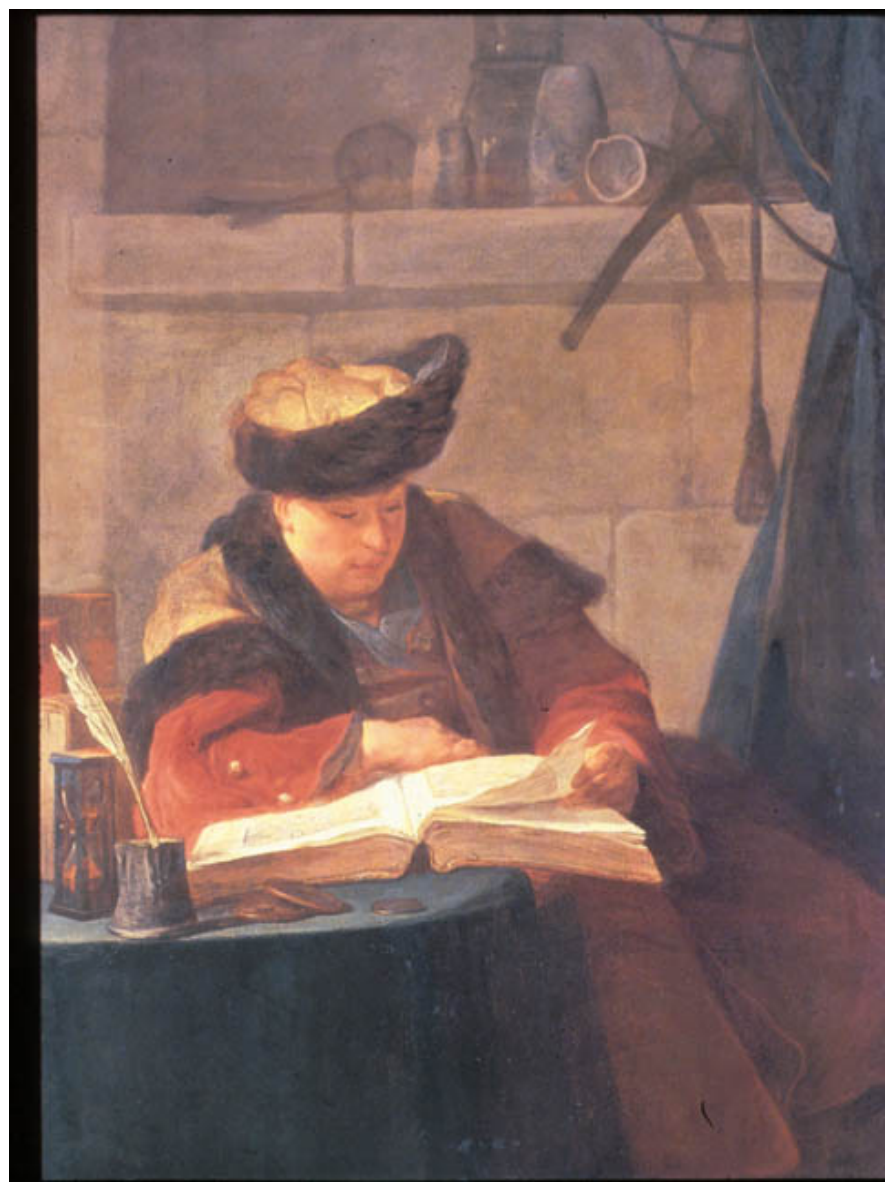

Figura 1 - Le Philosophe Lisant, de Chardin (1734)

Fonte: Wikimedia Commons (2020).Disponível em: https://commons.wikimedia.org/wiki/ File:Jean-Baptiste_Siméon_Chardin___Le_philosophe_lisant.jpg. Acesso em: 30 jul. 2020

Steiner ([1996] 2018, p. 35) conclui seu ensaio afirmando a necessidade de resgatar o caminho para a "arte da leitura", professando o seguinte: "se une lecture bien faite passar a ser apenas um artifício do passado, um enorme vazio passará a ocupar nossas vidas e teremos perdido para sempre a serenidade e a luz que emanam da tela de Chardin". O ensaio foi publicado em 1996 no Brasil, quando o leitor já pouco se parecia com o 
leitor incomum e com Le Philosophe Lisant, este último descrito pelo autor e pintado por Chardin em 1734. O leitor da década de 1990 já era o leitor da memória atrofiada, que não mais identificava passagens da literatura fundadora; um leitor que submerge em uma espécie de "amnésia planejada", nas palavras de Steiner (2018, p. 30).

Não podemos discordar do autor: não somos dotados de fácil memorização de literatura a ponto de citá-la e descrevê-la fielmente, livres de material de consulta, e estamos profundamente envolvidos em um processo de hiperinformação de toda sorte. Como afirma o filósofo Byung-Chul Han (2017), nossa sociedade é a do cansaço. A memorização e a hiperestimulação imagética, sonora, virtual parecem não andar juntas, não se somam. Em especial, cansa-nos, sem nos darmos conta disso, a necessidade de produzir constantemente para sermos valorizados, em uma espécie de autovaloração pelo quanto fazemos.

De fato, não há mais o leitor incomum de Steiner (2018). O leitor de hoje, reconhecemos, é também sujeito de desempenho, que

[...] está livre da instância de domínio exterior que o obrigue ao trabalho e o explore. [...] O sujeito de desempenho acaba entregando-se à coação livre a fim de maximizar seu desempenho. Assim ele explora a si mesmo. Ele é o explorador e ao mesmo tempo o explorado, o algoz e a vítima, o senhor e o escravo. O sistema capitalista mudou o registro da exploração estranha para a exploração própria, a fim de acelerar o processo. O sujeito de desempenho, que se imagina como soberano de si mesmo, como homo liber, aparece como homo sacer. O sujeito de desempenho, como soberano, mostra-se homo sacer de si mesmo (HAN, 2017, p. 105).

Porque o leitor de hoje é simultaneamente um sujeito de desempenho, instiga-nos, em especial, esta reflexão: a que estão se dispondo os que se reúnem para ler um clássico em grupo, em voz alta? Problematizemos, entấo, sobre o leitor que há e que está em constante processo de modificação. Pensemos sobre este leitor que, inserido em uma sociedade cujo indivíduo busca libertar-se do outro, porque livre, paradoxalmente vai ao encontro de uma experiência de vivência do outro, para escutá-lo e para falar-lhe, em um exercício totalmente desvinculado de produtividade.

\section{O leitor incomum de 2020}

Fechamos as portas de casa para a Covid-19, isolando-nos. Leitores 
habituais seguiram voltando-se aos seus livros (em tela ou impressos), mas foram privados do convívio social, seja para lazer, seja no trabalho, seja em instituiçóes de ensino. Depois da experiência com a leitura de clássicos em voz alta no campus da universidade, os leitores dos tempos de isolamento social, antes participantes do projeto de extensão, passaram a ler em voz alta em salas virtuais, para seguirem fazendo o que nos parece ser o elo entre eles nessa nova leitura: a necessidade comum de, "ao ler um livro, interromper com frequência a leitura, não por desinteresse, mas, ao contrário, por afluxo de ideias, excitaçóes, associaçóes" (BARTHES, 2012, p. 26). Trata-se, entretanto, de um levantar de cabeça que busca não somente um diálogo com o texto lido: o leitor ultrapassa o simples processar do texto, e levanta a cabeça sobretudo em busca de associaçôes de sentido feitas pelo outro, que se entrelaçarão às suas.

Cabe explicarmos aqui que os próprios participantes solicitaram a retomada dos encontros do grupo de leitura, dispostos a tentar o exercício da fruição da leitura neste novo ambiente: o virtual, em salas de encontro do Skype criadas pelos próprios estudantes, com regularidade, em dias e horários fixos. Os leitores trouxeram consigo convidados que não haviam vivido a experiência da leitura em voz alta em grupo. Assim, com suas câmeras abertas, os leitores incomuns de 2020 introduziram, em suas rotinas de quarentena, o encontro com o livro e com o outro em uma relaçáo por vezes até mais íntima do que o encontro físico para a leitura em grupo, antes realizada no campus da universidade. A câmera tornou-se a janela para o que era antes privado, onde só acontecia a leitura solitária e silenciosa, cuja interrupção era feita "por afluxo de ideias, excitaçôes, associações" somente do leitor, que tinha seu livro como única companhia.

Destacamos, nesse sentido, a riqueza das trocas realizadas desde março de 2020, que ilustraram o que nos aponta Cecília Bajour (2012, p. 24) em Ouvir nas entrelinhas: o valor da escuta nas práticas de leitura:

escutar, assim como ler, tem que ver [...] com a vontade e com a disposição para aceitar e apreciar a palavra dos outros em toda sua complexidade, isto é, não só aquilo que esperamos, que nos tranquiliza ou coincide com nossos sentidos, mas também o que diverge de nossas interpretaçóes ou visóes de mundo. A escuta não resulta da manifestação coletiva do dizer de cada um. Não é questão de que todos tenham a palavra caso esta acabe no burburinho da autocomplacência. Escutar para reafirmar uma verdade que só olha para si mesma e espera a palavra do outro somente para enaltecer a própria palavra é a antítese do diálogo, e não raro comporta intençôes de poder e controle sobre os sentidos trazidos à tona. 
A asserção da autora se evidencia não só na prática, nos encontros de $1 \mathrm{~h} 30$ em que o grupo se dedica à leitura e à discussão, como também na reflexáo sobre a ação por parte dos jovens estudantes, de 19 a 35 anos, que participam do grupo. Já idos quatro meses dessa experiência nesse novo processo de ler e discutir leituras, convidamos os participantes a responderem a duas questôes no intuito de termos acesso às suas impressóes sobre esse exercício, que entendemos táo coletivo quanto individual. Tivemos testemunhos - denominação mais adequada do que respostas, ao nosso ver -, que serão a seguir discutidos, gerados pelas seguintes questôes: 1) $\mathrm{O}$ que te motivaste a participar do grupo de leitura na modalidade online e, ainda, o que te motivaste a permanecer no grupo ao invés de seguir a leitura individual do clássico?; 2) Escreve um parágrafo curto sobre como avalias essa experiência. Reportamos, a seguir, alguns trechos para legitimar nossa reflexão:

O que me motivou a participar do grupo de leitura na modalidade on-line foi a experiência anterior da leitura em grupo, feita na modalidade presencial. [...] Quando leio sozinha e nâo entendo alguma coisa ou acho algum trecho interessante, não há debate - a discussão termina em mim ou em alguma anotação que eu faça no livro. Já na leitura em grupo, quando alguém tem alguma dúvida, discutimos sobre a questão, buscamos respostas, ouvimos o que o outro tem a dizer sobre o assunto, e às vezes passamos mais tempo debatendo do que de fato lendo - o que torna a leitura mais lenta, mas também mais proveitosa. Dessa forma, ficamos mais próximos da história do livro, reclamamos dos personagens, criamos carinho pela obra, trazemos exemplos que vivemos, falamos de nós. Essa troca entre os participantes me mostrou o quanto a leitura do clássico pode criar sentimentos diferentes em leitores diferentes. A reação dos outros participantes durante a leitura faz com que eu preste atenção em trechos que talvez passassem despercebidos por mim. Quando alguém para de ler ou comenta alguma coisa, minha atenção volta-se para o trecho em questáo e passo a enxergá-lo de um novo ângulo. É essa multiplicidade de discussóes e de pontos de vista que torna a leitura em grupo uma experiência motivadora para mim. Passei não só a ler o clássico, mas também a falar sobre ele e sobre o que ele emerge.

Recorte 1 - Participante A

Identificar a leitura do clássico em grupo como uma oportunidade de prestar atenção no que poderia passar despercebido, de fazer uma leitura mais atenta e aprofundada e, especialmente, de ter vontade de retornar ao texto quando dele levantamos a cabeça ("Quando alguém para de ler ou comenta alguma coisa, minha atenção volta-se para o trecho em questão e passo a enxergá-lo de um novo ângulo"), parece-nos razão suficiente 
para considerarmos o grupo de leitura em voz alta um empreendimento importante. Relacionamos essa percepção do participante ao que nos diz Bajour (2012, p. 25): "falar dos textos é voltar a lê-los". Vicente Jouve (2002, p. 109), em A leitura, lembra-nos de que "uma das experiências mais emocionantes da leitura consiste em proferir mentalmente ideias que não são nossas"; e enfatiza: "ser quem não somos [...] tem algo de desestabilizante". Trata-se da perturbadora interiorizaçáo do outro. A leitura em grupo, por sua vez, permite-nos ultrapassar essa relação, e nos deparamos com a interiorização do outro pelo outro.

Analisemos o trecho de mais um testemunho:

Também era muito interessante, ao lermos diálogos, ouvir as vozes dos personagens da história personificadas na voz de algum colega do grupo; cada colega colocava sua própria interpretação da história em sua voz, realçando certas características do personagem e atribuindo certas nuances, o que me levou, várias vezes, a contemplar um mesmo personagem de diferentes maneiras ao longo da leitura.

Recorte 2 - Participante B

A ênfase dada pelo participante à personificação da voz das personagens por meio das diferentes leituras feitas pelos colegas do grupo remeteu-nos à leitura interpretada pelo adulto quando ainda não líamos a palavra escrita por conta própria, como nos lembra Michèle Petit (2019, p. 78) em Ler o mundo: experiências de transmissáo cultural nos dias de hoje: "nos primeiros tempos da vida humana, é a mãe quem fala à criança, ou a pessoa que lhe dedica os cuidados maternos. Ela fala do mundo, ela sonha junto à criança. E a palavra vale antes de tudo por suas modulaçóes, seu ritmo, seu canto".

O gesto de ler para o outro requer doação, pois cuida de que o outro compreenda o lido. No caso da leitura para leitores que leem, temos um estatuto de leitura para o outro com outra especificidade: damos voz a uma leitura que pode ser diversa da nossa - uma riqueza inalcançável por meio da leitura individual e silenciosa.

O testemunho a seguir destaca o isolamento social como motivador para os encontros virtuais de um integrante que não participava, como outros que integram o grupo on-line, do grupo de leitura presencial este proposto com caráter de extensão. A leitura literária é uma atividade que habitualmente se realiza em isolamento, o que de fato colabora para elencarmos a situação de pandemia como fator motivador importante para o interesse em participar de um grupo de leitura virtual. 
Para a leitura do Idiota, a primeira que participei, o que mais me motivou foi o fato de ser uma atividade rotineira e que eu poderia fazer com pessoas conhecidas, duas coisas que, nesse período de isolamento social, eu sentia mais falta (rotina e amigos). Percebo duas vantagens de ler coletivamente (sobre ler sozinho). A primeira é o senso de compromisso. [...] A segunda é o efeito das impressóes e comentários alheios: frequentemente existem passagens ou elementos que numa leitura normal eu não daria atenção, mas que eu percebo mais atentamente quando outra pessoa reage àquilo, o que me possibilita encontrar novas coisas no livro para gostar ou só pensar sobre.

Recorte 3 - Participante C

Assim como o testemunho anterior, o trecho a seguir reforça a mobilização viabilizada pela situação de isolamento: "os principais motivos que me levaram a participar do grupo de leitura foram, em primeiro lugar, as pessoas do grupo. Em segundo lugar, foi a necessidade de ter uma troca de experiências com as pessoas, ainda mais nesse momento de pandemia”.

A necessidade de estabelecimento de rotina (sobre o que muito se falou nas mídias durante o período de isolamento social) parece ter contribuído para que a leitura se tornasse habitual a alguns participantes, como nos diz este testemunho:

Fiquei sabendo do grupo de leitura pelo convite de um amigo. [...] Comecei a participar por ver no grupo um motivo para manter o hábito de ler textos de mais profunda interpretação, pois como aluno de computação, os materiais de estudo habituais tendem a ser muito objetivos, contribuindo para desenvolver o aluno, mas não para desenvolver o leitor. [...] $\mathrm{O}$ que me motivou a permanecer no grupo de leitura $[. .$.$] foi ver que muito mais longe$ se chega com um hábito do que com a vontade.

Recorte 4 - Participante D

Diante dos testemunhos sobre uma atividade inicialmente despretensiosa, cabe-nos destacar o interesse de pesquisa viabilizado por essa prática social que se estabeleceu em tempos de crise. No princípio, havia um grupo de leitura. Com quatro meses de encontros virtuais para a leitura de clássicos, alguns participantes da área de Letras interessaram-se pelo grupo também como objeto de pesquisa. Além disso, grupos menores se formaram para leitura de textos voltados à mediação de leitura, à formação de leitores, a círculos de leitura, com vistas ao estudo metalinguístico do que vivenciavam na prática. 


\section{Consideraçóes sobre um novo quadro a ser pintado}

Optar pela leitura de clássicos à distância em um período de crise não foi uma motivação cuja justificativa fosse dar seguimento à leitura que se vinha fazendo presencialmente, posto que a leitura interrompida pela pandemia não pôde ser continuada em virtude de os livros terem ficado no campus da universidade, que está de portas fechadas. O grupo que se constituiu para ler em plataforma on-line - formado, como dito, por alguns participantes do projeto de extensáo que ocorria presencialmente e também por novos integrantes, seus convidados - justifica-se por querer (e se dispor a) realizar a leitura de clássicos no período de isolamento social. Os leitores incomuns de 2020 voltaram-se aos clássicos e às telas por trás das quais havia o outro, com quem puderam experienciar práticas sociais ainda que a distância.
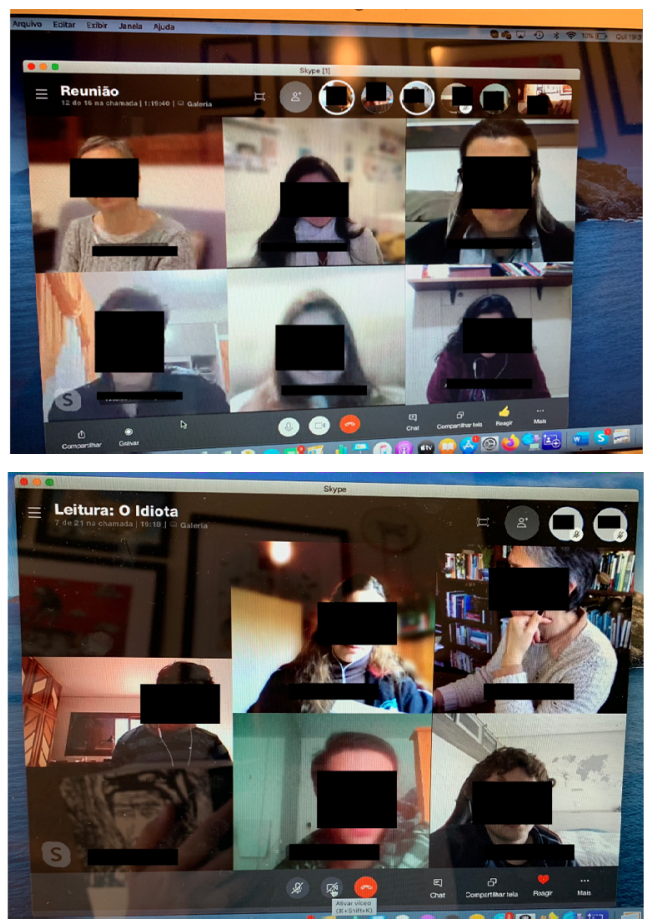

Figura 2 - Registro fotográfico do grupo de leitura on-line Fonte: Capturas de tela feitas pelas autoras (2020) 
A escolha pelos clássicos não foi feita sem interferência: houve proposição de alguns títulos pela coordenadora do projeto de extensão presencial, e a definição da obra foi feita pelo grupo. E, se houve proposição, cabe ressaltarmos que a escolha da leitura não pode ser definida como não condicionada; mas alguma escolha - ainda que aparentemente individual não o é?

Como afirma Gallian (2017, p. 86-87, grifo nosso), um clássico

[...] pode ser algo excessivamente pesado e difícil para se enfrentar sozinho. Por outro lado, se vivenciadas as dificuldades iniciais da falta de hábito e compreensão, o grande poder mobilizador da leitura do ponto de vista afetivo e reflexivo praticamente exige uma dinâmica de expressão e compartilhamento, concretizado numa situaçáo de interlocuçáo, para que esse processo amplificador ocorra de forma saudável e produtiva do ponto de vista da humanização.

Os testemunhos de fato assinalaram a escuta como um importante diferencial desse tipo de leitura. Sabemos que a construçáo de sentidos nunca é individual, mas a possibilidade de discutir a obra lida em tempo real, embora não seja menos complexa que a leitura individual, torna o processo mais dinâmico e, em vez de determinar significados, expande-os coletivamente.

Le Philosophe Lisant (cf. Figura 1) é um quadro a ser apreciado, olhando para o seu tempo. Do nosso tempo, o retrato revelado é o da Figura 2: com leitores munidos de seus aparelhos celulares, seus computadores, seus fones de ouvido, seu e-reader ou seu livro impresso, seu lápis, seu material de consulta e seus marcadores de página dos mais diversos tipos, cores e formatos. Leitores que buscam o outro em tempos de isolamento social. Esse é o retrato de um ritual de leitura destes tempos, pois Le Philosophe Lisant nos é possível como arte a ser apreciada, enquanto o nosso ritual é o de vivência da arte literária nos moldes oferecidos por 2020.

Reforçamos, portanto, o potencial da escolha por ler clássicos coletivamente, como uma maneira de dar maior dimensão ao papel humanizador da literatura. A alteridade dialógica se torna mais ampla se realizada em um grupo; especialmente, em um grupo de leitores em isolamento social por motivaçóes externas à sua vontade, um grupo de leitores incomuns de 2020, os leitores da pandemia.

\section{Referências}


BAJOUR, Cecília. Ouvir nas entrelinhas: o valor da escuta nas práticas de leitura. Tradução: Alexandre Morales. São Paulo: Editora Pulo do Gato, 2012.

BARTHES, Roland. O rumor da língua. Tradução: Mario Laranjeira. 3. ed. São Paulo: WMF Martins Fontes, 2012.

BENJAMIN, Walter. O narrador: consideraçóes sobre a obra de Nikolai Leskov. In: BENJAMIN, Walter. Magia e técnica, arte e política: ensaios sobre literatura e história da cultura. Tradução: Sérgio Paulo Rouanet. 8. ed. revista. São Paulo: Brasiliense, [1936] 2012. v. 1, p. 213-240. (Obras Escolhidas).

CALVINO. Ítalo. Por que ler os clássicos. 6a reimp.Tradução: Nilson Moulin. São Paulo: Companhia das Letras, [2002] 2018.

COMPAGNON, Antoine. Literatura para quê? Tradução: Laura Taddei Brandini. Belo Horizonte: Editora UFMG, 2012.

FLORES, Valdir do Nascimento. Sujeito (2). In: FLORES, Valdir do Nascimento et al. (org.). Dicionário de linguística da enunciaçáo. São Paulo: Contexto, 2009. p. 220.

GALLIAN, Dante. A literatura como remédio: os clássicos e a saúde da alma. São Paulo: Martin Claret, 2017.

HAN, Byung-Chul. Sociedade do cansaço. Tradução: Enio Paulo Giachini. 2. ed. ampliada. Rio de Janeiro: Vozes, 2017.

JOUVE, Vicente. A leitura. Tradução de Brigitte Hervot. São Paulo: Editora Unesp, 2002.

PETIT, Michèle. A arte de ler ou como resistir à adversidade. Tradução: Arthur Bueno e Camila Boldrini. São Paulo: Editora 34, 2009.

PETIT, Michèle. Ler o mundo: experiências de transmissão cultural nos dias de hoje. Tradução: Julia Vidile. São Paulo: Editora 34, 2019.

PUCHNER, Martin. O mundo da escrita: como a leitura transformou a civilização. Tradução: Pedro Maia Soares. São Paulo: Companhia das Letras, 2019.

STEINER, George. O leitor incomum. In: STEINER, George. Nenhuma paixáo desperdiçada. Tradução: Maria Alice Máximo. 2. ed. Rio de Janeiro: Record, [1996] 2018. p. 13-35.

TODOROV, Tzvetan. A literatura em perigo. Tradução: Caio Meira. 9. ed. Rio de Janeiro: Difel, 2019. 